GEOPHYSICAL RESEARCH LETTERS, VOL. 17, NO. 8, PAGES 1187-1190, JULY 1990

\title{
MOMENT TENSOR RATE FUNCTIONS FOR THE 1989 LOMA PRIETA EARTHQUAKE
}

\author{
Larry J. Ruff and Bart W. Tichelaar
}

Department of Geological Sciences, The University of Michigan

\begin{abstract}
The fault plane and overall coseismic slip of the 1989 Loma Prieta, California, earthquake $\left(M_{S}=7.1\right)$ are well determined [Plafker and Galloway, 1989]. Teleseismic waves can be used to determine the time history of moment release. We invert a data set of ten broadband $P$ and $S H$ waves for the most general point source description: the five moment tensor rate functions. The linear inversion also provides formal estimates of model uncertainty. While the moment tensor rate functions suggest a different focal mechanism for the first few seconds of the rupture process, it is not statistically significant at the $95 \%$ level. We can thus proceed to invert for one single time function (the source time function), and five scalars (the moment tensor). The major double couple that we find (strike $138^{\circ} \pm 6^{\circ}$ clockwise from North, dip $76^{\circ} \pm 5^{\circ}$, slip angle $120^{\circ} \pm 10^{\circ}$ ) agrees with the results of Plafker and Galloway [1989]. The minor double couple is small (1\%). The best point source depth is about $10 \mathrm{~km}$. Several broadband $P$ waves show that a small precursor occurred a few seconds before the main pulse of moment release. The duration of the source time function is $9 \mathrm{~s}$, with a moment of $2+0.5 \times 10^{19} \mathrm{Nm}$. A bilateral rupture with velocity of 2.8 $\mathrm{km} / \mathrm{s}$ and $9 \mathrm{~s}$ duration encompasses the aftershock region.
\end{abstract}

\section{Introduction}

The 1989 Loma Prieta, California, earthquake (PDE hypocentral parameters: $37.036^{\circ} \mathrm{N}, 121.883^{\circ} \mathrm{W}$, depth $19 \mathrm{~km}$, $\mathrm{M}_{\mathrm{S}}=7.1$; origin time 18 OCT $0^{\mathrm{h}} 4^{\mathrm{m}} 15.2^{\mathrm{s}} \mathrm{GMT}$ ) apparently ruptured a $50 \mathrm{~km}$ segment of the San Andreas fault system in central California. Other contributions to this special issue will document the tectonic setting, shaking damage, etc. This paper is focused on the focal mechanism and rupture time history of the earthquake. The earthquake occurred in a region of dense geophysical instrumentation. As a consequence, the basic fault plane geometry and rupture extent are well established. Hence, the focal mechanism is "known", and the seismic moment can be estimated from the geodetic control on fault slip. For most magnitude 7 earthquakes that occur around the world, observations of seismic waves are used to determine the focal mechanism and seismic moment. Thus the Loma Prieta earthquake provides the opportunity to test our teleseismic waveform inversion methods against a "known" focal mechanism. Of course, there is one aspect of the earthquake process that can only be obtained from waveform studies: the time history of rupture. Although this earthquake appears to be a simple single-pulse event from the perspective of long

Copyright 1990 by the American Geophysical Union.

Paper number 90GL01343

$0094-8276 / 90 / 90 G L-01343 \$ 03.00$ period body waves, the new digital broad-band records clearly indicate a small precursor to the main event.

Plafker and Galloway [1989] published preliminary estimates for the fault geometry: strike $130^{\circ} \pm 8^{\circ}$ clockwise from North, dip $70^{\circ} \pm 10^{\circ}$, slip angle $130^{\circ} \pm 15^{\circ}$. The motion is about half thrusting and half right-lateral strike-slip. The hypocentral depth from their report is about $18 \mathrm{~km}$. The epicenter plots in the middle of the aftershock area (length approximately $50 \mathrm{~km}$ ), which implies a bilateral rupnure along the strike direction. The predicted directivity time shifts for teleseismic $P$ waves will only be a couple of seconds. Therefore, it is unlikely that teleseismic waves can resolve the spatial variations in moment release. An equivalent point source is the most reasonable representation of the Loma Prieta earthquake with respect to teleseismic $P$ and $S H$ waves.

\section{Moment Tensor Rate Functions (MTRFs)}

The most general description of a seismic source allows the six independent moment rate density functions to vary arbitrarily in both time and space throughout the source volume. The complete spatial-temporal history of moment release can never be resolved from teleseismic waveform analysis [see, e.g., Aki and Richards, 1980]. It is necessary to discretize the fault surface into a small number of spatial compartments. As mentioned above, perhaps only one spatial compartment can be resolved for the Loma Prieta earthquake. Thus, the description of the seismic source is reduced to just five independent moment tensor rate functions (hereafter: MTRFs), where we have also eliminated the isotropic part of the moment tensor. It is common to further reduce the source description to just one function, the source time function, and five numbers, the moment tensor. Furthermore, when using waves that have a dominant period greater than the duration of the source time function, the problem is reduced to determining only the five numbers of the moment tensor plus the best spatialtemporal location of the point source. The Harvard group [see, e.g., Dziewonski and Woodhouse, 1983] has shown that the five numbers of the moment tensor can be reliably and systematically determined by inverting "entire" longperiod seismograms. In addition, Sipkin and colleagues [see Sipkin, 1986] have systematically determined moment tensors based on inversion of $P$ and $S H$ waves. It is also possible to use iterative procedures to find the moment tensor, source time function and focal depth [e.g., Barker and Langston, 1982; Nabelek, 1984; Ward, 1983].

We want to keep the most general point-source description for our study of the Loma Prieta event, i.e., the five MTRFs. This allows the possibility of a time-varying focal mechanism. Derivations of the equations for teleseismic $P$ and $S H$ waves can be found in various sources [e.g., Ali and Richards, 1980; Stump and Johnson, 1977]. We will 
give an abbreviated treatment. The moment tensor is decomposed into five independent double couple sources (Table 1 ), that vary arbitrarily with time. We refer to these

Table 1. The five independent double couple sources

\begin{tabular}{cccc}
\hline $\begin{array}{c}\text { strike } \\
\left.{ }^{\circ}\right]\end{array}$ & $\begin{array}{c}\text { dip } \\
{\left[{ }^{\circ}\right]}\end{array}$ & $\begin{array}{c}\text { slip } \\
{\left[{ }^{\circ}\right]}\end{array}$ & $\begin{array}{c}\text { non-zero moment } \\
\text { tensor components }\end{array}$ \\
\hline 0 & 45 & -90 & $\mathrm{~m}_{11}=-\mathrm{m}_{33}$ \\
90 & 45 & -90 & $\mathrm{~m}_{22}=-\mathrm{m}_{33}$ \\
0 & 90 & 0 & $\mathrm{~m}_{12}=\mathrm{m}_{21}$ \\
180 & 90 & -90 & $\mathrm{~m}_{13}=\mathrm{m}_{31}$ \\
90 & 90 & -90 & $\mathrm{~m}_{23}=\mathrm{m}_{32}$ \\
\hline
\end{tabular}

Moment tensor component indices are for a cartesian coordinate system at the epicenter, with "1","2", and "3" corresponding to "East", "North", and "up".

five functions as $f_{1}(t)$ through $f_{5}(t)$, and their physical units are moment rate $\left(10^{20} \mathrm{Nm} / \mathrm{s}\right)$. For a particular seismogram of a body wave phase observed at a certain station $k, s_{k}(t)$, the synthetic seismogram, $\tilde{s}_{k}(t)$, is constructed as:

$$
\sum_{i=1}^{5} g_{k i}(t) * f_{i}(t)=\tilde{s}_{k}(t)
$$

where the symbol * stands for convolution. In other words, each seismogram results from the sum of the unknown five MTRFs convolved with the five "known" Green's functions, $g_{k i}(t)$, for that particular station. Given a total of $\mathrm{K}$ body wave seismograms, we have the following symbolic system of equations:

$$
\left[\begin{array}{c}
g_{11}(t) *, \cdots, g_{15}(t) * \\
\dot{v} \\
g_{K 1}(t) *, \cdots, g_{K 5}(t) *
\end{array}\right]\left[\begin{array}{c}
f_{1}(t) \\
\cdot \\
f_{5}(t)
\end{array}\right]=\left[\begin{array}{c}
\tilde{s}_{1}(t) \\
\cdot \\
\cdot \\
\cdot \\
\tilde{s}_{K}(t)
\end{array}\right]=\left[\begin{array}{c}
s_{1}(t) \\
\cdot \\
\cdot \\
\cdot \\
s_{K}(t)
\end{array}\right]
$$

We can obtain discretized estimates for the unknown functions, $f_{1}(t) \cdots f_{5}(t)$, from the observed seismograms by minimizing the mismatch between synthetic and observed seismograms. This inverse problem is basically the simultaneous deconvolution of five functions, thus it is assured that the problem is poorly conditioned. We use the damped Lancsoz generalized inverse for time domain inversion with damping parameter d (see Ruff [1989]). Because the inversion is linear, data variance can be mapped into model space, and the model resolution can be formally assessed.

The primary seismological relevance of the five MTRFs is that this representation allows the focal mechanism to change with time during the rupture process. The five MTRFs span a model space that is almost five times larger than the model space for one source time function and a moment tensor, and the fit to the data will always be better for the larger model space. Therefore, we need to assess if the increase in data fit defines temporal variations in the faulting geometry that are statistically significant. A weighted average of the five functions defines the best single source time function (see Vasco [1989] for a different approach). If the rescaled single source time function then falls within the error bounds of the individual five MTRFs, the single time function is an adequate representation of the earthquake rupture, i.e., there are no statistically significant temporal changes in the faulting geometry. In this case, the best resolved moment tensor associated with the single source time function is found by re-inverting the seismograms for the five moment tensor components.

\section{Results for the Loma Prieta earthquake}

Ten broadband body wave phases are used in our analysis. The broadband seismograms are from GDSN, CSN, IRIS and GEOSCOPE [Romanowicz et al., 1984] stations (Figure 1). Given the heterogeneous mixture of digital instrument responses, it is necessary to rescale both seismograms and Green's functions [see Tichelaar and Ruff, 1990]. The rescaling normalizes the instrument responses to the same average spectral amplitude in the

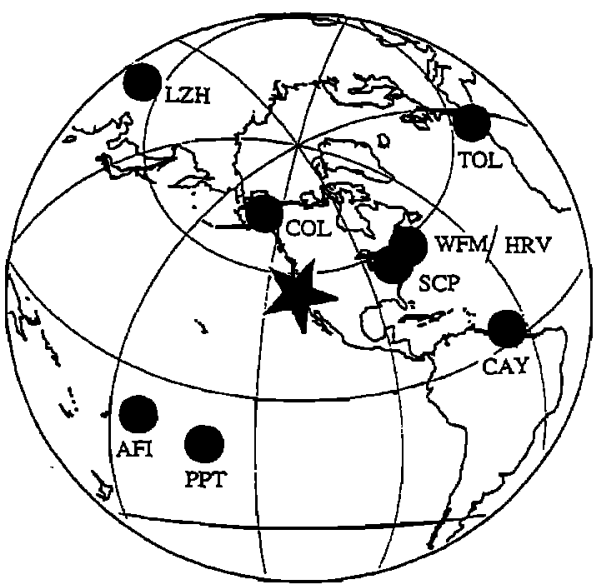

Fig. 1. Epicenter (star) of the 1989 Loma Prieta earthquake, station locations (dots) and codes of the stations used in this study. The azimuthal equal distance projection is centered on the epicenter, with a map radius of $100^{\circ}$.

bandpass of 10 to $30 \mathrm{~s}$ (all plots of the seismograms show the correct relative amplitudes after rescaling). The Green's functions are calculated for a source region with a $P$ velocity of $6.7 \mathrm{~km} / \mathrm{s}$, a density of $2.7 \mathrm{~g} / \mathrm{cm}^{3}$, and a Poisson's ratio of $1 / 4$, and include the free surface reflections. The MTRFs are composed of straight line segments with a $1 \mathrm{~s}$ spacing and a total duration of $15 \mathrm{~s}$; the duration of the inverted seismograms is $30 \mathrm{~s}$. The seismograms were smoothed in accordance with the time function interval.

Figure 2 shows the error parameter as a function of assumed point source depth, both for the inversion for the five MTRFs $(d=0.4)$ and for the undamped $(d=0)$ moment tensor re-inversion. The best point source depth is 10-12 $\mathrm{km}$. Figure 3 then shows the error bounds ( \pm two standard deviations) of the five MTRFs around the mean, together with the average single source time function that has been individually scaled to each MTRF. The scaled single source time function falls within the error bounds of the individual MTRFs, which means that there is no statistical evidence at the $95 \%$ significance level for a time-varying moment tensor. If we are willing to accept a less stringent statistical test, then the differing character of the five MTRFs in the first few seconds suggests a time-variable focal mechanism. 


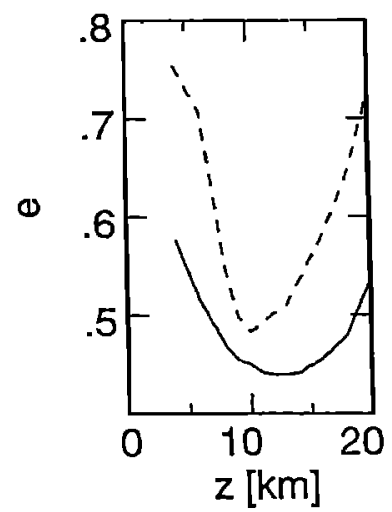

Fig. 2. Data misfit (e, the ratio of error vector length to data vector length) versus the assumed point source depth, 2. Two error curves are shown: inversion for the five moment tensor rate functions (solid), and inversion for the moment tensor (dashed). The best depth is 10 to $12 \mathrm{~km}$.

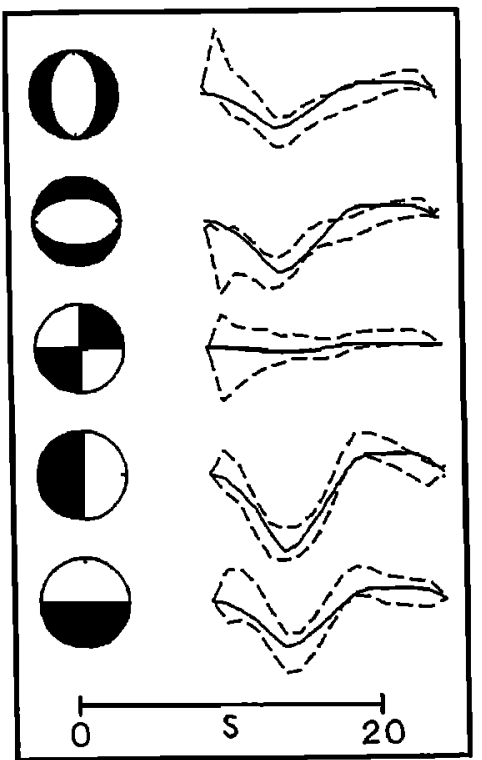

Fig. 3. Statistical test for time-varying moment tensor. The average single source time function (solid traces) is scaled to best-fit each moment tensor rate function, and is plotted together with the error bounds (dashed traces) about the five MTRFs. The scaled single source time function falls within the error bounds of the individual MTRFs, which means that there is no statistical evidence at the $95 \%$ significance level for a time-varying moment tensor.

We shall return to this notion later, but here we emphasize that a different initial focal mechanism is not statistically significant, according to our criterion.

Given the above conclusion that a single time function is a statistically acceptable description, we can proceed to analyze the moment tensor that results from the reinversion. Table 2 lists the moment tensor components of the Loma Prieta event and their standard deviation, calculated for a depth of $10 \mathrm{~km}$. The resultant major double couple is shown in Figure 4 (strike $138^{\circ} \pm 6^{\circ}$, dip $76^{\circ} \pm 5^{\circ}$, slip angle $120^{\circ} \pm 10^{\circ}$ ). The minor double couple is quite small
Table 2. The five independent moment tensor components

\begin{tabular}{cccccc}
\hline & $\mathbf{m}_{11}$ & $\mathbf{m}_{22}$ & $\mathbf{m}_{12}$ & $\mathrm{~m}_{13}$ & $\mathrm{~m}_{23}$ \\
\hline mean & $\mathbf{0 . 0 4 2}$ & -0.113 & -0.041 & -0.108 & -0.070 \\
s.d. & 0.021 & 0.055 & 0.022 & 0.007 & 0.008 \\
\hline
\end{tabular}

Units are $10^{20} \mathrm{Nm}$; s.d. is a posteri standand deviation.

(1\%). The results for a depth of $12 \mathrm{~km}$ are not significantly different. Note that the focal mechanism determined from the ten broadband body waves agrees with the results of Plafker and Galloway [1989]. Figures 4 and 5 show the single source time function, which is basically one dominant pulse with a small precursor. The moment rate reaches its maximum in $5 \mathrm{~s}$, and the total duration of rupture is $9 \mathrm{~s}$. If we assume that the rupture process was a symmetric bilateral rupture that fills the aftershock region, the average rupture velocity is about $2.8 \mathrm{~km} / \mathrm{s}$. On the other hand, it is possible that the main pulse of moment release was released in a smaller region of the aftershock area. The seismic moment is $2+0.5 \times 10^{19} \mathrm{Nm}\left(\mathrm{M}_{\mathrm{W}}=6.8\right)$.

Broadband $P$ waves display some details of rupture initiation for the Loma Prieta earthquake. A more detailed time function is deconvolved from two broadband $P$ waves. The sampling interval of the source time function is

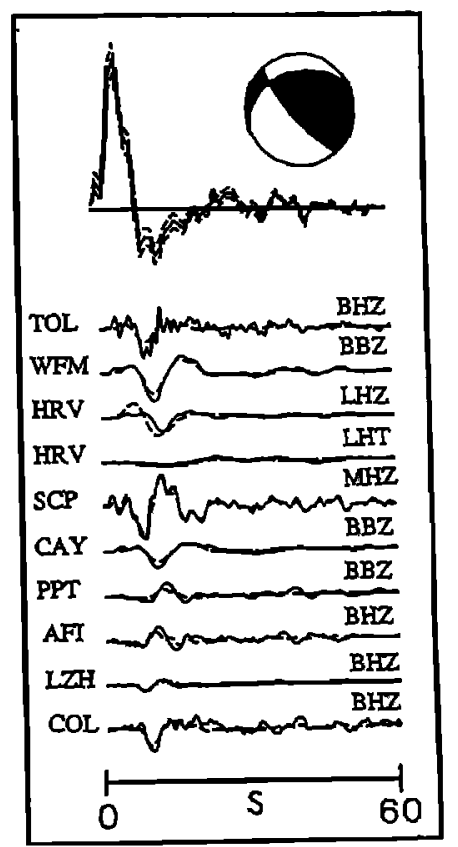

Fig. 4. Focal mechanism of the Loma Prieta earthquake derived from our moment tensor inversion is shown at the top (strike $138^{\circ} \pm 6^{\circ}$, dip $76^{\circ} \pm 5^{\circ}$, slip angle $120^{\circ} \pm 10^{\circ}$ ). Upper part of the figure shows the single source time function (solid trace), plotted together with its error bounds (dashed) of one standard deviation. Lower part of the figure shows the ten broadband phases (solid traces) and their synthetic counterparts (dashed traces). The seismograms are labeled with their station code on the left, and the component code on the right ( $\mathrm{Z}$ means $P$ wave on vertical, $\mathrm{T}$ stands for $S H$ wave on tangential). 


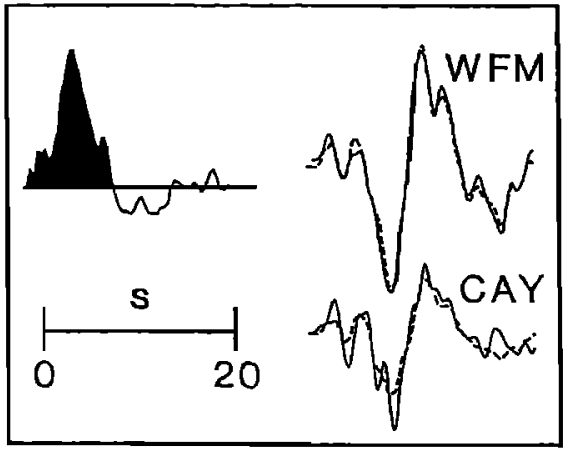

Fig. 5. A more detailed look at the source time function (left), obtained by inverting two broadband $P$ waves (right) with a time interval for the source time function of $0.4 \mathrm{~s}$. Rupture initiates with a small precursor in the first $3 \mathrm{~s}$.

$0.4 \mathrm{~s}$. Seismograms are smoothed in accordance with this finer time sampling. The results (Figure 5) indicate that the main pulse has a small distinct precursor of about $3 \mathrm{~s}$ duration, with a moment release that is $10-15 \%$ of the total moment. In detail, these $\boldsymbol{P}$ waves show that this precursor has an even smaller precursor in the first second or so.

Let us recall that the MTRFs offer the suggestion that the small precursor may have a different mechanism than that for the dominant pulse. As one test of this suggestion, we calculate a focal mechanism for the precursor event based on the MTRFs of Figure 3. A moment tensor based on the relative amplitudes of the five functions at $1 \mathrm{~s}$ gives a major double couple with a strike of $147^{\circ}$, dip $86^{\circ}$, slip $184^{\circ}$. This mechanism represents nearly pure right-lateral strike-slip along the same trend as the overall mechanism. Although the precursor introduces some complications in the first few seconds of rupture, we emphasize that a timevarying focal mechanism is not statistically significant.

\section{Conclusions}

We have inverted a data set of ten teleseismic broadband body waves for the five MTRFs of the 1989 Loma Prieta earthquake. The results indicate that a single moment tensor and source time function are a statistically adequate representation of the rupture history. The reduction to a major double couple (minor double couple is $1 \%$ ) gives the following focal mechanism: strike $138^{\circ} \pm 6^{\circ}$, dip $76^{\circ} \pm 5^{\circ}$, slip angle $120^{\circ} \pm 10^{\circ}$. The best point source depth is about 10 $\mathrm{km}$, for a crustal $P$ velocity of $6.7 \mathrm{~km} / \mathrm{s}$. The seismic moment release is $2+0.5 \times 10^{19} \mathrm{Nm}$. The source time function consists of a small precursor pulse of $3 \mathrm{~s}$ duration, followed by the single dominant pulse, for a total duration of $9 \mathrm{~s}$. Assuming that the rupture process was a symmetric bilateral rupture, the average rupture velocity is $2.8 \mathrm{~km} / \mathrm{s}$.
Acknowledgments. Earthquake research at the University of Michigan is supported by the National Science Foundation (EAR8720935). We thank Jiajun Zhang and Barbara Romanowicz for their help with digital data.

\section{References}

Aki, K., and P.G. Richards, Quantitative Seismology, Volume 1, 558 pp., W.H. Freeman and Company, San Francisco, California, 1980.

Barker, J.S., and C.A. Langston, Moment tensor inversion of complex earthquakes, Geophys. J. R. Astron. Soc., 68, 777-803, 1982.

Dziewonski, A.M., and J.H. Woodhouse, An experiment in systematic study of global seismicity: centroid-moment tensor solutions for 201 moderate and large earthquakes of 1981, J. Geophys. Res., 88, 3247-3271, 1983.

Nabelek, J.L., Determination of earthquake source parameters from inversion of body waves, Ph.D. thesis, 346 pp., Mass. Inst. Tech., 1984.

Plafker, G., and J.P. Galloway, editors, Lessons learned from the Loma Prieta, California, earthquake of October 17, 1989, U.S.G.S. circular 1045, Government Printing Office, Washington, D.C., 48 pp., 1989.

Romanowicz, B., M. Cara, J.F. Fels, and D. Rouland, GEOSCOPE: A French initiative in long-period three component seismic networks, EOS, 65, 753, 1984.

Ruff, L.J., Multi-trace deconvolution with unknown trace scale factors: Omnilinear inversion of $P$ and $S$ waves for source time functions, Geophys. Res. Lett., 16, 1043-1046, 1989.

Sipkin, S.A., Interpretation of non-double-couple earthquake mechanisms derived from moment tensor inversion, J. Geophys. Res., 91, 531-549, 1986.

Stump, B.W., and L.R. Johnson, The determination of source properties by the linear inversion of seismograms, Bull. Seism. Soc. Am., 67, 1489-1502, 1977.

Tichelaar, B.W., and L.J. Ruff, Rupture process and stress drop of the great 1989 Macquarie Ridge earthquake, Geophys. Res. Lett., 17, in press, 1990.

Vasco, D.W., Deriving source-time functions using principal component analysis, Bull. Seism. Soc. Am., 79, 711-730, 1989.

Ward, S.N., Body wave inversion: moment tensors and depths of oceanic intraplate bending earthquakes, J. Geophys. Res., 88, 9315-9330, 1983.

L. Ruff and B. Tichelaar, Dept. Geological Sciences, University of Michigan, Ann Arbor, MI 48109.

(Received April 12, 1990; accepted June 5, 1990.) 